JURNAL ILMIAH KEBIDANAN IMELDA

Vol.7, No.2, September 2021, pp.85-89

ISSN: 2597-7180 (Online), 2442-8116 (Print)

http://jurnal.uimedan.ac.id/index.php/JURNALKEBIDANAN

\title{
GAMBARAN PENGETAHUAN IBU HAMIL TENTANG TEKNIK MENYUSUI YANG BENAR DI DUSUN ABDI GUNA LANGKAT TAHUN 2021
}

\author{
Rahmawani Fauza \\ Universitas Imelda Medan, Indonesia
}

\begin{tabular}{l}
\hline \hline Article Info \\
\hline Article history: \\
Received Sep 06, 2021 \\
Revised Sep 20, 2021 \\
Accepted Sep 28, 2021
\end{tabular}

\section{Keywords:}

Knowledge

Formula Milk

\begin{abstract}
Formula milk is milk made from real cow's milk or artificial milk by changing its composition which can be used as a substitute for breast milk. Formula milk can be used as a substitute for breast milk or can also be complementary to breast milk. But it must be remembered that none of the nutritional compositions can resemble breast milk. This study aims to better understand and know the advantages and disadvantages of giving formula milk to babies. This research is descriptive in nature using primary data by dividing the questionnaire and tabulating it to get the results. The population of this study were all mothers in Neighborhood IX Bandar Selamat Subdistrict, Medan Tembung District with a total population of 30 respondents and using the Total Sampling technique as many as 30 respondents. Have less knowledge in junior high school as many as 8 respondents $(27 \%)$, based on the type of work the majority have less knowledge on housewives as many as 11 respondents (37\%), and based on information sources the majority have less knowledge of getting information and electronic media as many as 8 respondents $(26 \%)$. Based on the results of this study, it can be concluded that the mother's level of knowledge regarding formula feeding at the age of 0-6 months is in the poor category. Therefore, knowledge greatly influences mothers to achieve the Exclusive Breastfeeding program. Therefore, it is hoped that mothers can increase their knowledge about the advantages and disadvantages of formula feeding.
\end{abstract}

This is an open access article under the CC BY-SAlicense.

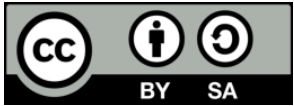

\section{Corresponding Author:}

Rahmawani Fauza,

Program Studi S1 Kebidanan,

Universitas Imelda Medan,

Jl. Bilal No. 52 Kelurahan Pulo Brayan Darat I Kecamatan Medan Timur, Medan - Sumatera Utara.

Email: rahmawani.29@gmail.com

\section{INTRODUCTION}

Menyusui ialah seni yang harus dipelajari kembali, keberhasilan dalam menyusui tidak diperlukan alat khusus dan biaya yang besar. Yang harus diperlukan hanya sebuah kesabaran, waktu dan pengetahuan mengenai menyusui dan dukungan. Menyusui adalah suatu proses alamiah, namun walupun merupakan proses yang alamiah harus memiliki pengetahuan dan latihan yang tepat dalam melaksankan teknik menyusui (Rinata, 2016).

Menyusui selain memberikan makanan padat bayi juga membantu membentuk ikatan cinta yang kuat antara ibu dan bayinya, meskipun demikian masih banyak wanita yang belum mengetahui bagaimana 
cara menyusui efisien khususnya mereka yang baru petama kali mempunyai anak (Moody, 2006). Walaupun menyusui merupakan sesuatu hal yang alamiah, bagi beberapa para ibu bisa saja mengalami hambatan dalam pelaksanaannya. Terkadang faktor fisik penyebabnya seperti melahirkan dengan operasi Caesar. Tapi mungkin juga karena baru pertama kali mempunyai anak, sehingga anda kurang memahami bagaimana cara agar air susu bisa keluar lancar (Nichol, 2005).

Badan Kesehatan Dunia (WHO), sebagai contoh, mendorong para wanita untuk menyusui bayinya secara eksklusif selama 6 bulan dan melanjutkan menyusui hingga setidaknya 2 tahun untuk mendapatkan keuntungan dari kemampuan ASI dalam memberikan nutrisi terbaik dan melindunginya dari infeksi (Nichol, 2005). UNICEF memperkirakan bahwa menyusui sampai berusia 6 bulan dapat mencegah kematian 1,3 juta anak berusia dibawah 5 tahun. Penelitian Ghana yang dipublikasikan dalam jurnal Pediatrics menunjukkan 16\% pencegahan kematian bayi dengan menyusui sehak pertama kelahirannya. Angka ini dapat naik 22\% jika menyusui dilakukan 1 jam awal sesudah lahir bayi tersebut (Prasetyono, 2009).

Hanya di Indonesia $80 \%$ ibu menyusui bayinya sampai umur 6 bulan dan $4 \%$ ibu yang menyusui bayinya dalam 1 jam setelah lahir, padahal sekitar 21.000 kematian bayi yang lahir dengan usia dibawah 28 hari dapat dicegah dengan pemberian ASI. Pemberian ASI ekslusif juga dapat mengurangi angka kematian bayi sampai 13\% sehingga dengan asumsi jumlah penduduk 219 jiwa, jumlah angka kelahiran 22/1000 kelahiran hidup, angka kematian balita 46/1000 kelahiran, maka jumlah bayi yang akan terselamatkan sebanyak 30 ribu. Namun sangat disayangkan tingkat dalam memberikan ASI eksklusif hingga saat ini masih sangat rendah yakni antara 39-40\% dari jumlah ibu yang melahirkan. Kurangnya promosi pemberian ASI dan cara menyusui yang benar (http://grahacendikia.wordpress.com).

Dari penelitian yang dilakukan di Jawa Timur bayi yang diberi ASI sampai bayinya berumur 6 bulan pada tahun 2006 sebanyak 278.601(38,7\%) dengan jumlah bayi 719.332 jauh dibawah target sebanyak 60\% dari ibu-ibu itu tersebut tidak pernah mendapatkan informasi khusus tentang menyusui dan kurangnya pelayanan konseling laktasi dari petugas kesehatan (http://grahacendikia.wordpress.com).

Menurut profil kesehatan kota Medan (2006) bayi yang memperoleh ASI langsung 0-6 bulan sebanyak 866 bayi sebesar $7 \%$ dari 12.476 jumlah bayi yang ada di kota Medan. Ini kemungkinan banyaknya ibu yang bekerja sehingga tidak memberi ASI kepada bayi hingga usia 6 bulan (Profil Kesehatan Kota Medan, 2006).

Dari survey awal yang dilakukan di Dusun Abdi Guna Langkat terdapat 518 jiwa, 169 kepala keluarga dan diantaranya dijumpai ibu hamil dan masih rendahnya pengetahuan ibu hamil tersebut tentang bagaimana teknik menyusui yang benar. Berdasarkan latar belakang diatas, maka peneliti berminat untuk melakukan penelitian tentang "Gambaran Pengetahuan Ibu Hamil Terhadap Teknik Menyusui yang Benar di Dusun Abdi Guna Langkat Tahun 2021.

\section{RESEARCH METHOD}

Penelitian ini dilakukan di Dusun Abdi Guna Langkat. Penelitian ini memiliki jumlah populasi sebanyak 30 orang. Jenis penelitian yang digunakan adalah deskriptif dengan metode metode total sampling, yaitu dengan menggunakan data primer yang dikumpulkan melalui pengisian kuesioner. Ini digunakan untuk mengetahui gambaran pengetahuan ibu hamil tentang teknik menyusui yang benar.

\section{RESULTS AND ANALYSIS}

3.1 Hasil

Setelah melakukan penelitian yang berjudul "Gambaran Pengetahuan ibu Hamil Tentang Teknik Menyusui yang Benar di Dusun Abdi Guna Langkat Tahun 2021" berdasarkan umur, pendidikan dan sumber infomasi diperoleh data yang disajikan dalam bentuk tabel sebagai berikut.

\section{Distribusi Responden Berdasarkan Pengetahuan}

Tabel 1. Distribusi Frekuensi Pengetahuan Ibu Hamil Tentang Teknik Menyusui yang Benar di Dusun Abdi Guna Langkat Tahun 2021

\begin{tabular}{clcc}
\hline No & Pengetahuan & F & \% \\
\hline 1 & Baik & 5 & 16,67 \\
\hline 2 & Cukup & 9 & 30 \\
\hline 3 & Kurang & 16 & 53.33 \\
\hline & Total & $\mathbf{3 0}$ & $\mathbf{1 0 0}$
\end{tabular}

Dari tabel 1 dapat dilihat pengetahuan ibu dalam teknik menyusui yang benar kebanyakan berpengetahuan kurang sebabnyak $16(53,33 \%)$ sedangkan sedikit yang berpengetahuan baik $5(16,67 \%)$ responden. 


\section{Distribusi Responden Berdasarkan Umur}

Tabel 2. Distribusi Frekuensi Pengetahuan Ibu Hamil Tentang Teknik Menyusui yang Benar Berdasarkan Umur di Dusun Abdi Guna Langkat Tahun 2021

\begin{tabular}{llcccccccc}
\hline \multirow{2}{*}{ No Umur } & \multicolumn{4}{c}{ Pengetahuan } & \multicolumn{2}{c}{ Total } \\
\cline { 3 - 9 } & & \multicolumn{2}{c}{ Baik } & \multicolumn{2}{c}{ Cukup } & \multicolumn{2}{c}{ Kurang } & & \\
\cline { 2 - 9 } & & F & $\mathbf{\%}$ & F & \% & F & \% & F & \% \\
\hline 1 & $<2$ & - & - & 1 & 3 & 3 & 10 & 4 & 13,33 \\
\hline 2 & $21-30$ & 3 & 10 & 6 & 20 & 9 & 30 & 18 & 60 \\
\hline 3 & $>30$ & 2 & 6,67 & 4 & 6,67 & 4 & 13,33 & 8 & 26,67 \\
\hline & Total & $\mathbf{5}$ & $\mathbf{1 6 , 6 7}$ & $\mathbf{9}$ & $\mathbf{3 0}$ & $\mathbf{1 6}$ & $\mathbf{5 3 , 3 3}$ & $\mathbf{3 0}$ & $\mathbf{1 0 0}$ \\
\hline
\end{tabular}

Dari tabel 2 dilihat bahwa pengetahuan ibu mengenaik teknik meyusui yang benar kebanyakan responden memiliki pengetahuan kurang pada umur 21-30 tahun dengan 9 (30\%) responden. Sedangkan minoritas responden berpengetahuan cukup pada umur $<20$ tahun sebanyak 1 responden $(3,33 \%)$.

\section{Distribusi Responden Berdasarkan Pendidikan}

Tabel 3. Distribusi Frekuensi Pengetahuan Ibu Hamil Tentang Teknik Menyusui yang Benar Berdasarkan Pendidikan di Dusun Abdi Guna Langkat Tahun 2021

\begin{tabular}{cccccccccc}
\hline \multirow{2}{*}{ No } & Pendidikan & \multicolumn{9}{c}{ Pengetahuan } & \multicolumn{2}{c}{ Total } \\
\cline { 3 - 10 } & & \multicolumn{2}{c}{ Baik } & \multicolumn{2}{c}{ Cukup } & \multicolumn{2}{c}{ Kurang } & & \\
\cline { 2 - 10 } & & F & $\mathbf{\%}$ & F & \% & F & \% & F & \% \\
\hline 1 & SD & 1 & 3,33 & 4 & 13,33 & 3 & 10 & 8 & 26,66 \\
\hline 2 & SMP & 2 & 6,67 & 3 & 10 & 4 & 13,33 & 9 & 30 \\
\hline 3 & SMA & - & - & 2 & 6,67 & 9 & 30 & 11 & 36,67 \\
\hline 4 & PT & 2 & 6,67 & - & - & - & - & 2 & 6,67 \\
\hline & Total & $\mathbf{5}$ & $\mathbf{1 6 , 6 7}$ & $\mathbf{9}$ & $\mathbf{3 0}$ & $\mathbf{1 6}$ & $\mathbf{5 3 , 3 3}$ & $\mathbf{3 0}$ & $\mathbf{1 0 0}$ \\
\hline
\end{tabular}

Dari tabel 3 dilihat bahwa pengetahuan ibu hamil dalam teknik menyusui yang benar dari aspek pendidikan banyak responden berpengetahuan kurang pada pendidikan SMA sebanyak 9 (30\%) responden.

\section{Distribusi Responden Berdasarkan Sumber Informasi}

Tabel 4. Distribusi Frekuensi Pengetahuan Ibu Hamil Tentang Teknik Menyusui yang Benar Berdasarkan Sumber Informasi di Dusun Abdi Guna Langkat Tahun 2021

\begin{tabular}{cccccccccc}
\hline \multirow{2}{*}{ No } & Sumber Informasi & \multicolumn{9}{c}{ Pengetahuan } & \multicolumn{2}{c}{ Total } \\
\cline { 3 - 8 } & & \multicolumn{2}{c}{ Baik } & \multicolumn{2}{c}{ Cukup } & Kurang & & \\
\cline { 2 - 8 } & & $\mathbf{F}$ & $\mathbf{\%}$ & $\mathbf{F}$ & $\mathbf{\%}$ & $\mathbf{F}$ & $\mathbf{\%}$ & $\mathbf{F}$ & $\mathbf{\%}$ \\
\hline 1 & TenagaKesehatan & 1 & 3,33 & 10 & 3 & 3 & 10 & 7 & 23,33 \\
\hline 2 & Media Massa & 2 & 6,67 & 1 & 3,33 & 10 & 33,33 & 13 & 43,33 \\
\hline 3 & KeluargaTeman & 2 & 6,67 & 5 & 16,67 & 3 & 10 & 10 & 33,33 \\
\hline & Total & $\mathbf{5}$ & $\mathbf{1 6 , 6 7}$ & $\mathbf{9}$ & $\mathbf{3 0}$ & $\mathbf{1 6}$ & $\mathbf{5 3 , 3 3}$ & $\mathbf{3 0}$ & $\mathbf{1 0 0}$ \\
\hline
\end{tabular}

Dari tabel 4 bahwa pengetahuan ibu dalam teknik menyusui dengan benar berdasarkan sumber informasi kebanyakan responden memiliki pengetahuan kurang dari media sebanyak 13 (43,33\%) dan sedikit yang berpengetahuan baik dari tenaga kesehatan dengan $1(3,33 \%)$ responden dan berpengetahuan cukup dari media massa sebanyak 1 responden $(3,33 \%)$.

\subsection{Pembahasan}

Setelah dilakukan penelitian mengenai Tingkat Pengetahuan Ibu Hamil Tentang teknik menyusui yang Benar di Dusun Abdi Guna Langkat Tahun 2021 dengan 30 responden berdasarkan pengetahuan umur, pendidikan dan sumber informasi, maka dapat disimpulkan sebagai berikut:

\section{Berdasarkan Pengetahuan Responden}

Hasil penelitian penulis yang disajikan pada tabel 1 diperoleh hasil kebanyakan responden berpengetahuan kurang sebanyak $16(53,33 \%)$ responden dan sedikit yang berpengetahuan baik sebanyak 5 responden (16,67\%). Penelitian (Notoatmodjo, 2005), pengetahuan adalah hasil "tahu" manusia hanya menjawab pertanyaan atau kemampuan ibu dalam menjawab pertanyaan ini terjadi setelah ibu melakukan penginderaan suatu objek tertentu. Penginderaan terjadi melalui indra pendengaran, penglihatan, rasa, raba maupun penciuman dan pengetahuan manusia diperoleh dari pendidikan, pengalaman sendiri maupun dari media massa.

Menurut asumsi penulis, dimana pengetahuan responden dalam kategori kurang karena sudah sering melihat atau mendengar gambaran pengetahuan tentang teknik menyusui yang benar, karena hanya sebagian 
ibu hamil yang mengetahui tentang tenik menyusui yang benar. Ini disebabkan mayoritas ibu hamil berpendidikan SD.

\section{Pengetahuan Berdasarkan Umur}

Berdasarkan hasil penelitiaan yang telah dilakukan dan telah dianalisa pada tabel 2 dilihat bahwa kebanyakan responden memiliki pengetahuan kurang pada usia 21-30 tahun dengan 9 (30\%) responden dan sedikit yang berpengetahuan cukup dengan usia < 20 tahun sebanyak 1 responden (3,33\%). Penelitian (Notoatmodjo, 2005) menyatakan bahwa umur mempunyai hubungan yang erat dengan pengetahuan karena semakin cukup umur, tingkat kematangan dan kekuatan akan semakin matang dalam berpikir dan bekerja.

Usia dewasa merupakan masa berprestasi. Selama usia ini orang akan mudah sukses dan sebaliknya dengan merasa berhenti dan tidak mempunyai kemauan yang tinggi unruk dapat berhasil dan masa persiapan keraj yang dilakukan sebelumnya. Ketika sudah dewasa muda, individu mencapai penguasaan ilmu pengetahuan dan ketrampilan yang sudah matang. Dengan modal itu seorang individu mampu memecahkan masalah secara sistematis dan mudah mengembangkan daya inisiatif-kreatif hingga akan memperoleh pengalaman dan semakin matang.

Menurut asumsi penulis umur mempunyai pengaruh terhadap pengetahuan ibu karena ibu yang berusia muda cenderung pengetahuannya lebih rendah, karena masih kurangnya pengalaman dan dengan bertambahnya usia itu maka pengalaman itupun semakin bertambah dan pengetahuan akan semakin baik.

\section{Pengetahuan Berdasarkan Pendidikan}

Hasil penelitian yang sudah dilakukan dan telah dianalisa pada tabel 3 bahwa kebanyakan responden memiliki pengetahuan kurang pada pendidikan SMA sebanyak 9 (30\%) responden dan sedikit responden berpengetahuan baik untuk SD dengan 1 responden (3,33\%). Hal ini menurut Notoatmodjo (2005) bahwa pendidikan merupakan proses belajar pada individu, kelompok, masyarakat yang berarti terjadi proses perkembangan atau perubahan arah yang lebih dewasa dan lebih matang.

Menurut (Notoatmodjo, 2005) Pendidikan adalah kegiatan yang dapat dilakukan dimana saja. Seorang dapat dikatakan belajar jika dalam dirinya terjadi perubahan diri yang tidak tahu menjadi tahu, dari yang tidak dapat mengerjakan menjadi dapat yang dikarenakan proses belajar, misalnya perkembangannya anak dari tidak bisa berjalan menjadi bisa. Perubahan ini terjadi karena bukan peroses belajar, tetapi karena proses kematangan. Menurut (Notoatmodjo, 2005) Pendidikan adalah jenjang formal yang telah diukur sesuai dengan waktu yang telah ditentukan.

Menurut asumsi penulis hasil penjelasan diatas bawa semakin tinggi tingkat pendidikan seseorang maka akan semakin mudah menerima ide, teknologi dan informasi terbaru khususnya dalam pengetahuan ibu hamil tentang teknik menyusui yang benar.

\section{Pengetahuan Berdasarkan Sumber Informasi}

Berdasrkan penelitian yang dilakukan dan telah dianalisa pada tabel 4 bahwa kebanyakan responden memiliki pengetahuan kurang dari media masa sebanyak 11 responden $(36,67 \%)$ dan sedikit responden dengan pengetahuan baik dari tenaga kesehatan 1 (3,33\%) dan pengetahuan cukup dari media masa sebanyak 1 responden $(3,33 \%)$.

Menurut (Notoatmodjo, 2005) sumber informasi merupakan alat yang membantu dalam melakukan kunjungan agar pendapat mengenai kesehatan masyarakat dapat diampaikan dengan jelas. Informasi kesehatan berasal dari petugas kesehatan pada umumnya bentuk pendekatan (cara) yang dilakukan petugas kesehatan adalah dengan cara penyuluhan atau ceramah melalui keluarga yaitu informasi didapat dari anggota keluarga atau orang terdekat disekitar melalui media massa kesehatan dapat berupa baku, surat kabar serta sumber percetakan lainnya, penyampaian informasi kesehatan yang tepat mempunyai peran tepat dalam meningkatkan pengetahuan individu seseorang.

Sumber informasi mempengaruhi pengetahuan baik dari media maupun orang dalam keterkaitannya dengan kelompok manusia memberi kemungkinan untuk mempengaruhi anggota - anggotanya. Menurut Notoatmodjo (2010) Umumnya massyarakat lebih percaya dengan informasi yang diterima dari orang lain yang mereka percaya. Hal terpenting adalah menentukan jenis media termasuk kombinasi media yang digunakan untuk mencapai sasaran (masyarakat) semakin banyak ibu memperoleh informasi maka semakin meningkat pengetahuan ibu.

Menurut asumsi penulis bahwa seseorang yang mendapat informasi yang banyak dengan sendirinya akan memiliki wawasan yang luas. Informasi diperoleh mencakup banyak aspek termasuk diantaranya pengetahuan ibu hamil tentang teknik menyusui yang benar akan bertambah. 


\section{CONCLUSION}

Dari hasil penelitian yang berjudul "Gambaran Pengetahuan Ibu Hamil Tentang Teknik Menyusui yang Benar di Dusun Abdi Guna Langkat Tahun 2021", maka dapat ditarik kesimpulan sebagai berikut:

1. Dari 30 responden yang diteliti mayoritas responden berpengetahuan cukup sebanyak 16 responden $(53,33 \%)$ dan minoritas respoden berpengetahuan baik sebanyak 5 responden $(16,67 \%)$.

2. Pengetahuan responden berdasarkan umur 21-30 tahun kebanyakan responden berpengetahuan kurang sebanyak 9 responden $(30 \%)$ dan minoritas responden berpengetahuan cukup pada umur $<20$ tahun sebanyak 1 responden $(3,33 \%)$.

3. Pengetahuan responden berdasarkan pendidikan mayoritas responden berpengetahuan kurang berdasarkan pendidikan SMA sebanyak 9 responden (30\%) dan minoritas responden berpengetahuan baik untuk SD sebanyak 1 responden $(3,33 \%)$.

4. Pengetahuan responden berdasarkan sumber informasi mayoritas responden berpengetahuan kurang memperoleh informasi dari media massa sebanyak 13 responden $(43,33 \%)$ dan minoritas responden bepengetahuan baik memperoleh informasi dari tenaga kesehatan sebanyak 1 responden $(3,33 \%)$ dan berpengetahuan cukup dari media massa sebanyak 1 responden $(3,33 \%)$.

\section{REFERENCES}

Ambarwati, dkk. 2009. Asuhan Kebidanan Nifas. Mitra Cendiakia: Jogjakarta

Arikunti. 2006. Prosedur Penelitian (Suatu pendekatan Praktek). PT. Rineka Cipta: Jakarta

Khasanah. 2011. ASI atau Susu Formula ya?. Flashbooks: Jogjakarta

Kristinasari. 2009. ASI Menyusui dan Sadari. Nuha Medika: Yogyakarta

Liewellyn. 2005. Setiap Wanita. Delapratasa Publishing: Jakarta

Maulana. 2009. Promosi Kesehatan. EGC: Jakarta

Mitayani. 2010. Mengenala Bayi Baru Lahir dan Penata Laksanaannya. Baduose Media: Padang-West Sumatara

Moody, dkk. 2006. Menyusui Cara Mudah Praktis dan Nyaman. Arcan: Jakarta

Nichol. 2005. Panduan Menyusui. PT. Prestasi Pustakarya: Jakarta

Notoatmodjo. 2005. Promosi Kesehatan (Teori dan Aplikasi). PT. Rineka Cipta: Jakarta

Novianti.2009. Menyusui Itu Indah. Octopus: Yogyakarta

Prawihardjo. 2008. Ilmu Kebidanan. PT.Bina Pustaka: Jakarta

Proverawati, dkk. 2010. Kapita Selekta ASI dan Menyusui. Nuh Medika: Yogyakarta

Saleha.2009. Asuhan Kebidanan Pada Masa Nifas. Salemba Medika: Jakarta

Siloma, V, Alvionita, P. 2021. Cara Menyusui Yang Benar Pada Bayi Berdasarkan Pengetahuan Dan Sikap Ibu. https://jurnal.stikes-aisyiyah-palembang.ac.id/index.php/Kep/article/view/615

Shelov. 2004. Perawatan Untuk Bayi dan Balita. Arcan: Jakarta

Rinata, E,dkk. 2016. Teknik Menyusui Posisi, Perlekatan Dan Keefektifan Menghisap - Studi Pada Ibu Menyusui Di Rsud Sidoarjo. https://media.neliti.com/media/publications/169879-ID-teknik-menyusuiposisi-perlekatan-dan-ke.pdf

\section{BIOGRAPHIES OF AUTHORS}

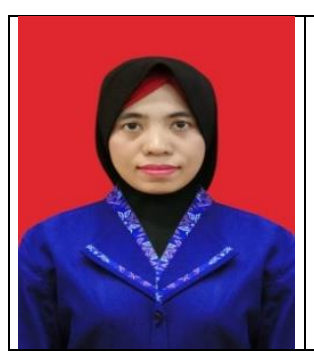

Rahmawani Fauza, Gelar D-III diperoleh dari Akademi Kebidanan Imelda Medan, Jurusan Kebidanan pada tahun 2007. Gelar D-IV diperoleh dari Universitas Sumatera Utara, Jurusan Bidan Pendidik pada tahun 2009. Magister Kesehatan Masyarakat diperoleh dari Universitas Sumatera Utara, Jurusan Kesehatan Masyarakat pada tahun 2018. Saat ini aktif sebagai dosen tetap di Prodi S1 Kebidanan Universitas Imelda Medan. 